\title{
Exploring Common Misconceptions and Errors about Fractions among College Students in Saudi Arabia
}

\author{
Yazan M. Alghazo ${ }^{1} \&$ Runna Alghazo ${ }^{1}$ \\ ${ }^{1}$ Humanities and Social Sciences, Prince Mohammad Bin Fahd University, Alkhobar, Kingdom of Saudi Arabia \\ Correspondence: Yazan M. Alghazo, Humanities and Social Sciences, Prince Mohammad Bin Fahd University, \\ Alkhobar, 31952, Kingdom of Saudi Arabia. Tel: 966-53-004-6438. E-mail: Yazan.alghazo@gmail.com
}

Received: November 14, 2016

Accepted: December 15, 2016 Online Published: March 30, 2017

doi:10.5539/ies.v10n4p133

URL: https://doi.org/10.5539/ies.v10n4p133

\begin{abstract}
The purpose of this study was to investigate what common errors and misconceptions about fractions exist among Saudi Arabian college students. Moreover, the study aimed at investigating the possible explanations for the existence of such misconceptions among students. A researcher developed mathematical test aimed at identifying common errors about fractions as well as short interviews, aimed at understanding the thought process while solving problems on the test, were conducted among a total of $107(\mathrm{n}=107)$ college students. The findings suggested that the majority of college students in Saudi Arabia hold common misconceptions about fractions and mathematical calculations involving fractions, such as thinking that all fractions are always part of 1 and never greater than 1 , and using cross multiplication to solve multiplication problems involving fractions.
\end{abstract}

Keywords: mathematical errors, fractions, common misconceptions

\section{Introduction}

The concept of fractions in mathematics has always been considered a difficult concept to understand by learners. Most learners have hard time thinking about fractions as numbers. They tend to see it only as a calculation on its own (division) or as a complex set of two numbers written on top of each other (Weinberg, 2001). That is why those learners use specific abstract rules to solve problems with fractions without really understanding the interpretations of these rules.

The reason why people think rational numbers are difficult to understand is most likely because they can be represented in different ways (parts of a whole, ratios, quotients). Research has shown that the majority of students find fractions to be too difficult and complex when involved in calculations; they find them difficult to visualize and to relate to their daily lives.

Mathematical learning is a systematic process that involves building on prior knowledge and mixing different skills and basic concepts in order to achieve mastery of mathematical calculations and procedures (Ashlock, 2001; Sarwadi \& Shahrill, 2014). It is, therefore, essential that teachers emphasize the importance of the basic concepts of mathematical understanding at early stages of learning, rather than focusing on memorization of rules and procedures using drill and practice techniques. Students construct their mathematical knowledge and build on previous knowledge they learn; this means that any misconception they develop as they learn mathematics might affect their future learning of similar related mathematical concepts (Vamvakoussy \& Vosniadou, 2010), therefore, it is essential that such misconceptions are identified as early as possible in order to guide students in changing those misconceptions and, hence, allow for future understanding of connected more complex concepts.

Researchers have investigated mathematical errors and misconceptions and found that students' mathematical errors lead to future hindering of their academic success in mathematically related topics (Sarwadi \& Shahrill, 2014). Vamvakoussi and Vosniadou (2010) conducted a study to investigate students' understanding of decimals, and concluded that students' understanding and conceptualization of decimals was robust and that students found it difficult to make the connection between decimals and fractions.

Because of the importance of learning fractions, and their use in people's daily lives (i.e. calculating tips for purchases, discounts, and sharing). The researcher attempts to explore the different misconceptions about fractions among college students. Moreover, this study attempts to shed light on the reasons that lead students to 
develop such misconceptions of fractions. Finally, the researcher proposes activities and methods that can be used to allow students to better understand fractions and to reduce the complexity they face when dealing with calculations involving fractions.

\section{Methodology}

\subsection{Instrument}

The researcher formulated a set of mathematical problems and questions, in the form a test, relating to fractions. The questions on the test were formulated based on previous literature about common misconceptions among students. The questions were aimed to measure the student's ability to perform the basic calculations (addition, subtraction, multiplication, and division) with fractions. The questions also aimed at addressing students' conceptual understanding of fractions (i.e. drawing visual representations of fractions). Also, to shed some light on their understanding of certain rules used in fraction calculations, and their perception of the difficulty of solving problems containing fractions. Some of the questions involved actual calculations, and others were written questions aimed to discover their general understanding of fractions.

\subsection{Participants}

The sample for the study included 107 college level students attending a four year university program in the Kingdom of Saudi Arabia. 77 of the students were male, and 30 were female. All the participants were freshman and sophomore students who have completed all university CORE mathematics courses, which are introduced prior to the students' entrance to their degree programs, including Introductory Algebra, Intermediate Algebra, Calculus I, and Calculus II. Table 1 shows the distribution of participants in the study per Gender and Year in college.

Table. 1. Distribution of participants based on Gender and Year in college

\begin{tabular}{lcc}
\hline Gender/Year & Freshman & Sophomore \\
\hline Male & 46 & 31 \\
Female & 21 & 9 \\
\hline
\end{tabular}

\subsection{Data Collection}

Data collection took place during regular class hours, where students were asked to volunteer in the study by completing the test and engaging in discussion with the researcher as they submitted their completed tests, the researcher went through the answers with the participants and asked them clarification questions about their methods and thinking process they utilized to solve the problems. Data were collected during Spring-2016 semester, and it took approximately two weeks to collect all data from participants. The purpose of the short interview was to shed more understanding on the students' thought process as they completed the items on the test. According to Vamvakoussi and Vosniadou (2010), interviewing students allows researchers to better understand the process of thinking involved in solving mathematical problems and, consequently, better identifying what misconceptions students hold, which lead to mathematical errors in solving problems.

\section{Results and Discussion}

Data analysis after grading the test revealed some common misconceptions among majority of students. Table 2 shows those common misconceptions and errors as well as their percentages among the participants. In the following sections, all of those common errors are discussed, as well as other common themes that emerged through the data analysis process.

Table 2. Common errors and misconceptions among college students

\begin{tabular}{lcc}
\hline Error/Misconception & No. of students & Percentage \\
\hline All fractions are always part of 1, never bigger than 1 & 88 & $83 \%$ \\
Multiplication makes numbers bigger, and division makes them smaller & 92 & $87 \%$ \\
Using cross multiplication to solve fraction multiplication problems & 60 & $57 \%$ \\
The larger the denominator the smaller the fraction regardless of nominator & 103 & $98 \%$ \\
\hline
\end{tabular}

“All fractions are always part of 1, never bigger than 1" (Mcleod \& Barbara, 2006). 
Most learners and students have this misconception, and the reason is because students do not view a fraction as a single number. They see fractions as either two numbers divided by each other, or a complex number written in a strange format that they are too difficult to conceptualize. When asked about this misconception, the majority of the students answered that it is true, and only 18 of them realized that it is not true that every fraction is less than 1 .

When a student sees a fraction that is greater than one, he or she does not think of it as a fraction but simply a division calculation. The students that answered true to the question about what they think about the fraction $6 / 3$ $=2$, and how this fraction proves the statement of all fractions being smaller than one wrong, their responses showed that they did not have a clear understanding of proper and improper fractions.

\section{Multiplication makes numbers bigger, and division makes them smaller:}

$87 \%$ of the participants also agreed with this statement; once the researcher asked them to explain how $6 \times 1 / 2=3$ fits with their assumption, they explained that they do not include fractions with general questions about mathematical operations. One of the student said "I only think of whole numbers, NOT fractions." Another student said that this is a rule he learned in school, and he did not pay attention to whether it can be generalized to fractions or not because "fractions are different."

This obviously indicates that students do not understand that fractions are part of the real numbers. They do not see fractions as single numbers on the number line; they have an assumption that they are different with special difficult rules.

To check if students see fractions as numbers on the number line (See Figure 1 for a number line that includes a fraction). Students were asked how many fractions there are between $1 / 2$ and $1 / 4$. Only twelve students answered infinity, which is the correct answer, and the rest gave answers that varied from one to 10 . That reveals either students' lack of understanding of the number line itself or that students see fractions as a division problem or a number too complicated to even be included in the number line, or along with other simpler numbers. This agrees with the findings of Vamvakoussi and Vosniadou (2010), who found that the majority of participants in their study were not able to determine how many decimals exist between 0.5 and 0.6. Similarly, Durkin and Rittle-Johnson (2015) conducted a study on student misconceptions and found that the majority of students are not able to place a number on the number line.

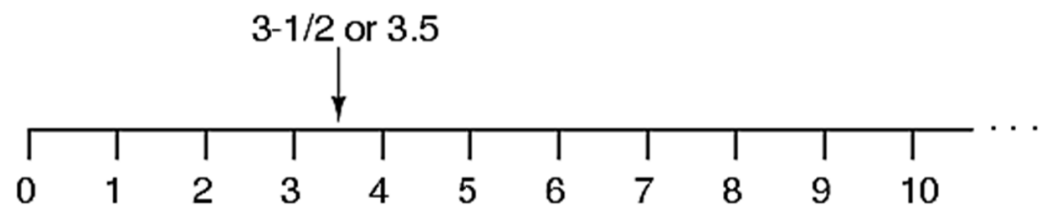

Figure 1. Number line that shows fractions

\section{Adding and subtracting Fractions:}

Most students find addition and subtraction of fractions tricky because of having to find a common denominator. However, 96\% of the participants answered the addition problem correctly. They were able to explain their answer and demonstrate how they calculated the common denominator first and then calculate the simple addition or subtraction. Some of the remaining students knew the answer for $1 / 2+1 / 4=.75$ but were unable to represent that number in fractions, and wrote it as $7 / 5$.

Also, students who could answer the question could also provide explanatory drawings of their answers (See Figure 2 for examples of students drawing representations of fraction addition). However, they used the same "rule" when asked to solve problems that contained fraction division and multiplication; which means that students memorize the "rules" they are taught about doing fraction calculations and sometimes they confuse those rules and over time this confusion ends up being a misconception about their basic skills with fractions. 


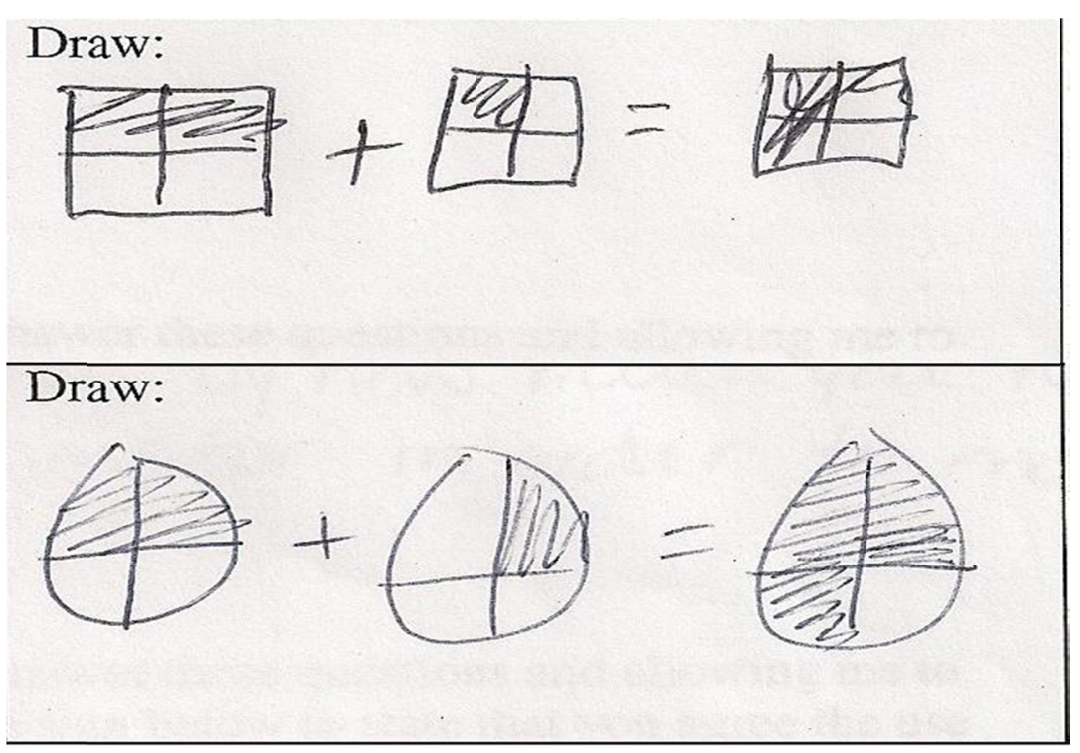

Figure 2(a). Drawing representations of $1 / 2+1 / 4$

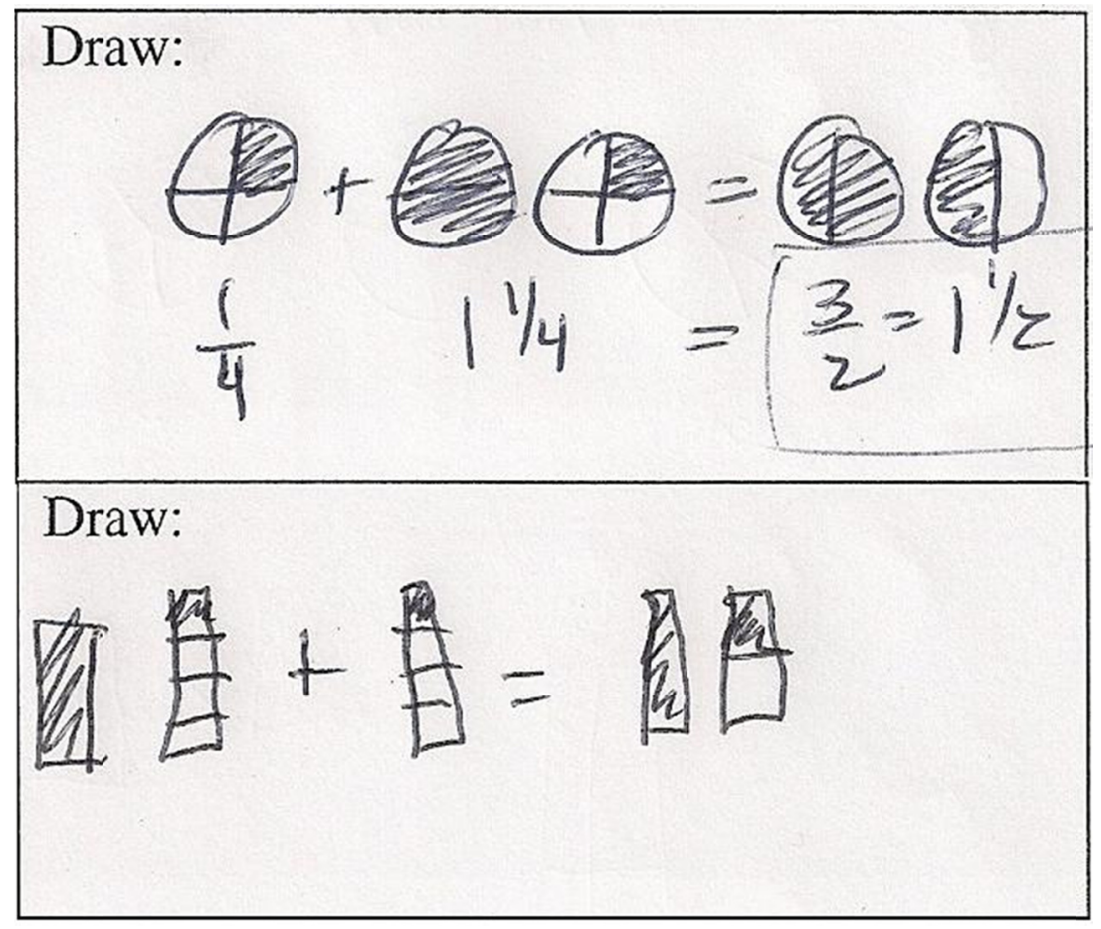

Figure 2(b). Drawing representations of $1 / 4+1 \frac{1 / 4}{4}$

\section{Multiplication and division of fractions:}

One of the students interviewed said: "Fractions aren't hard for me to do but I sometimes have problems multiplying them." Many of the students interviewed also agreed that division and multiplication are the hardest operation to deal with in problems involving fractions. Division of fractions has been described as one of the most complicated and least understood content domains (Aksu, 1997; Tirosh, 2000). It appears that the reason for this is that most students memorize the calculations performed on fractions as an abstract set of rules. Thus, since division is the rule with the most number of "steps" where you need to find the reciprocal of the second fraction and then multiply it by the first fraction; students find it the hardest to memorize and with time they tend to forget or get confused about which rule to use with which of the four basic operations.

Researchers believe that another reason why division is difficult for students is that students can only conceptualize dividing a larger number by a smaller number (Sadi, 2007). Only $43 \%$ of the participants solved 
the problem $3 / 5 \div 2 / 3$ correctly, and only $33 \%$ of those students could draw a reasonable pictorial representation of the equation. (See Figure 3 for pictorial representation on fraction division). This also indicates that even the students that solved the problem correctly did not understand exactly how they solved it. They only remembered the rules and explained it by saying "that's how I was taught to do it."

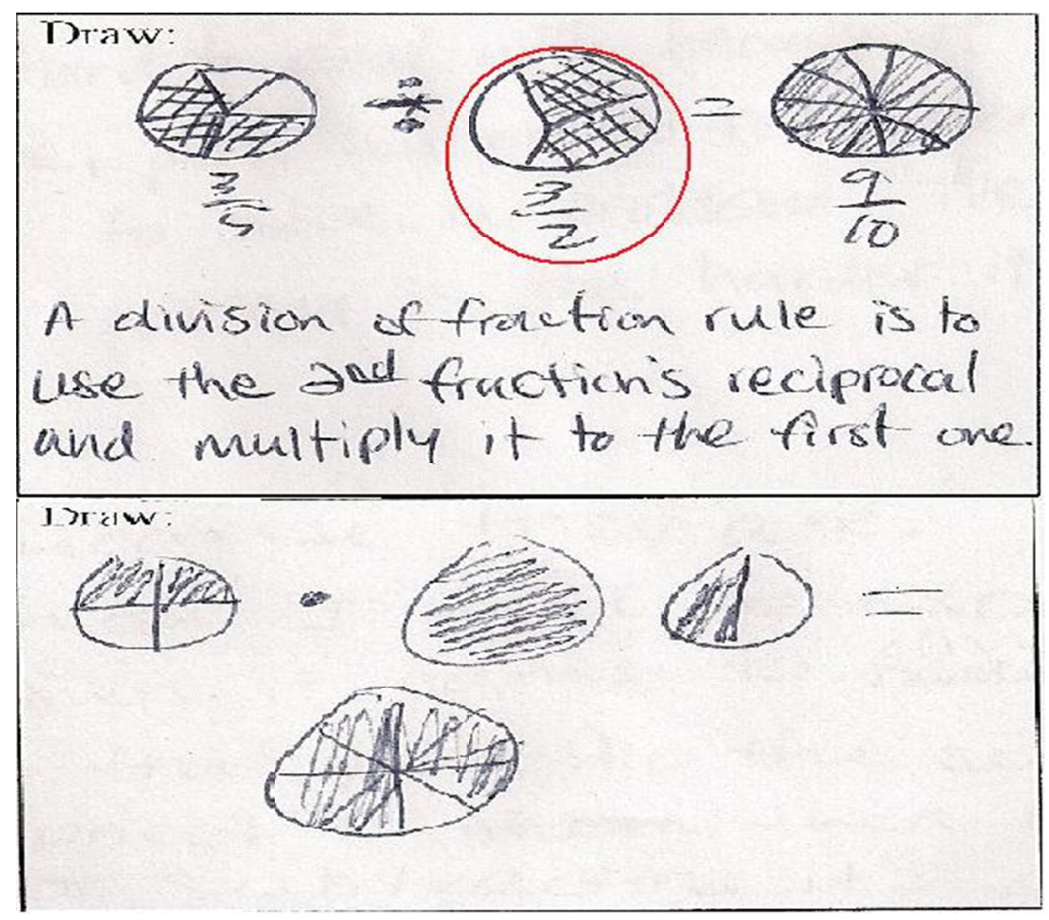

Figure 3. Different pictorial representations of $3 / 5 \div 2 / 3$

Another problem students solved incorrectly was the problem about multiplication. When asked to solve the problem $2 / 5 \times 3 / 4$, the majority of the students cross-multiplied and their answer was $8 / 15$ for this problem. After the researcher explained the correct answer to them, which would be $6 / 20$, most of them argued that they are used to utilizing calculators to solve such problems. They also said they were familiar with that rule but they just forgot it because they rarely used it.

\section{Weak conceptual understanding of the meaning of fraction:}

Another question on the test was to arrange a number of fractions in the order from the smallest to the biggest. The fractions were $4 / 5,1 / 3,5 / 4,4 / 9,1 / 2$. Only $2 \%$ answered correctly $(1 / 3,4 / 9,1 / 2,4 / 5,5 / 4)$, while $98 \%$ of the students gave very interesting answers that revealed misconceptions about students understanding of the actual representation of the fraction (the nominators and the denominator). This finding supports other research findings regarding comparing and ordering fractions, where students were found to have difficulty comparing fractions correctly (Durkin \& Rittle-Johnson, 2015).

The students seemed to think that the larger the denominator is the smaller the fraction is, no matter what the nominator is (see Figure 4 for example of students' answers to arranging fractions). The majority of the students who answered this question wrong had one of two explanations for their mistakes: one was that they believed that the denominator expressed "how many pieces there are" so the larger it is the smallest the number will be; One of the students explained this as a pizza slice representation. For example a pizza sliced into 9 pieces, so each piece is smaller than they would be if the same pizza was sliced into 5 pieces. What the students failed to see here is that a fraction not only represents the size of those slices of pizza, but also how many of them are available.

The second explanation was that they simply did not understand this representation of $x / y$ as quantity. They said that whenever they needed to solve such problems they would use the calculator to find out the answer, which the researcher found very interesting, because one of the students who actually found the correct answer could not solve the problem without first converting each one of the fractions into a percentage. 
Another interesting finding among all participants is that all of them with no exceptions took a considerable amount of time solving the problems in the questionnaire. The reason for that lack of problem solving skill with fractions is contributed to using calculators because $90 \%$ of the students, at one point, asked if they could use a calculator. They expressed they were uncomfortable trying to find the answers by paper pencil calculations. When the researcher asked some of them why they needed a calculator, their response was "It's a fraction problem."

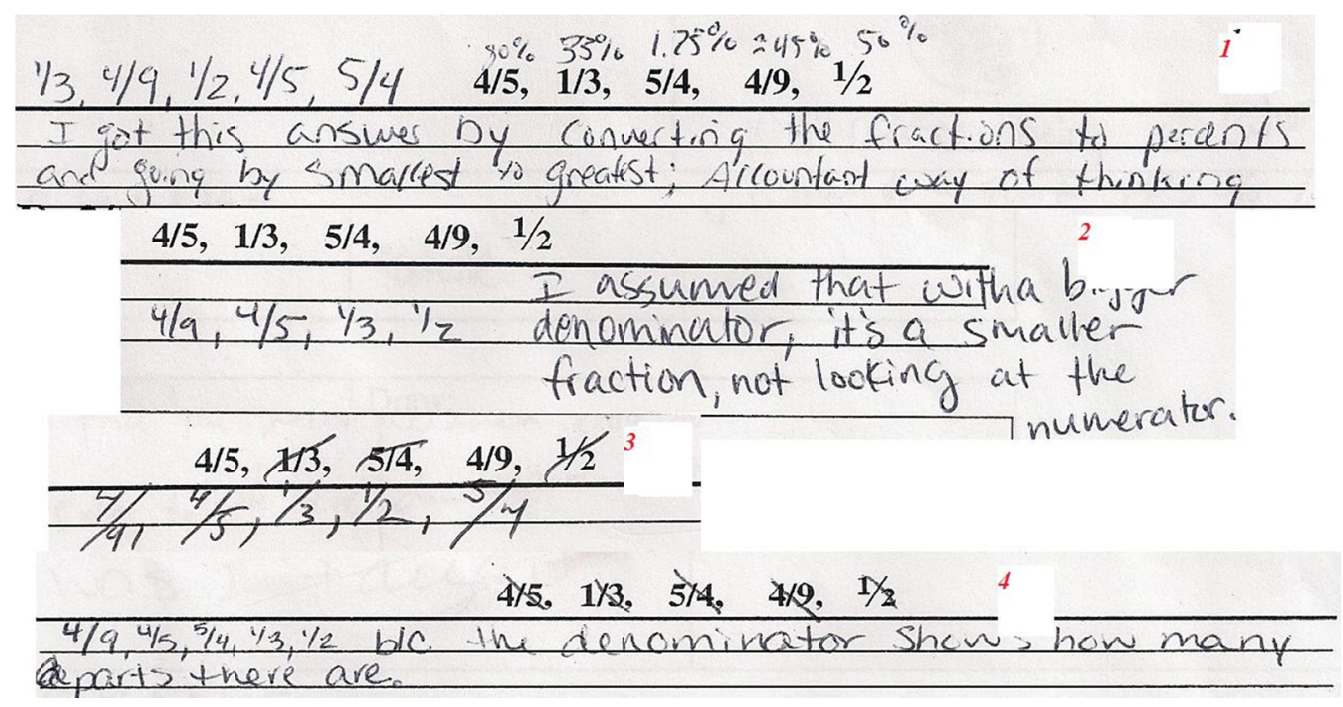

Figure 4. Examples of student's solutions to the question: Arrange these numbers from smallest to biggest. And explain why? $4 / 5,1 / 3,5 / 4,4 / 9,1 / 2$

One of the student's interviewed revealed more proof of some students' lack of understanding of nominators and denominators. The researcher asked him to represent the fraction $2 / 5$ for verbally and by drawing if possible. He said that the fraction 2/5 means: "two people sharing five apples", which clearly indicates he does not understand the relationship between the nominator and denominator. Which is the basis for understanding what a fraction is and what it represents (see Figure 5 for false representation of $2 / 5$ )?

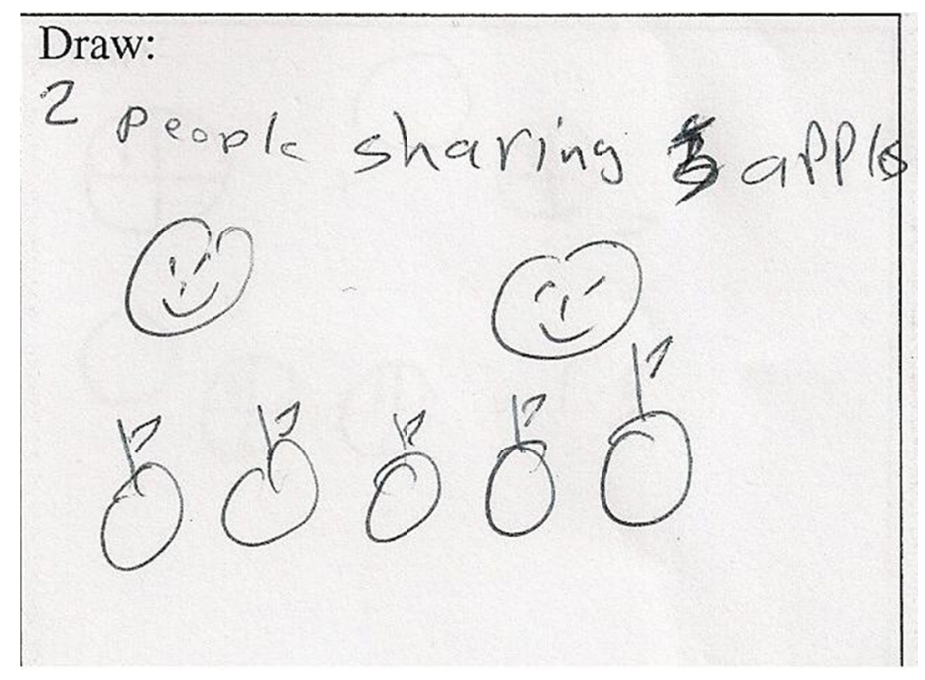

Figure 5. False representations of fraction 2/5

In order to understand why students develop misconceptions in fraction calculations, we need to investigate the 
reasons that students find fractions to be complicated and hard to understand. One of the most common reasons for this lack of ability to understand fractions is that students do not see fractions as real numbers. Hence, they find it difficult to solve problems that include more than one fraction because, for example, dividing a fraction by a fraction means that there are three division operations in the same problem. Which, eventually, makes them grow to dislike solving and dealing with such problems. Ahmed, one of the students interviewed said, "Fractions are just an annoyance. There is complications that every student finds when trying to solve them. Memory on how to solve them becomes repressed as one resents them more and more. I forgot how to divide them. Even as a math major, I wish they weren't so common in math courses."

Because students find fractions complicated, they spend more time trying to memorize the rules for calculations rather than spending time trying to understand them. This leaves those students with a very thin layer of knowledge regarding fraction calculations. And any memory loss of one of the rules will result in a misconception about that rule that might stay uncorrected for a long time, and even through their college years.

Allowing the use of calculators in schools has also added to this problem because students didn't need to work harder on fractions they could not understand. All they had to do is just punch in the numbers into the calculator; gradually this made students more dependent on calculators. And less eager to actually learn how to do the calculations as long as they can get the final answer, even if sometimes it doesn't make sense. This means that children's conceptual understanding of fractions will be reduced and hence, they will not be able to reach mathematical proficiency with fractions.

\section{Conclusion}

The purpose of this study was to explore the common mathematical misconceptions among college students about fractions. Since research shows that many of the problems students have with fractions are caused by their lack of understanding of fraction as real numbers, we need to find ways to help introduce fractions to students in a more simple and comprehendible manner. One approach for this is to start introducing fractions as pictorial and visual images long before the actual symbolic fraction format is introduced. This will help students gain a deeper understanding of the "part of whole" concept of fractions.

Another way to help students conceptualize fractions and the four operations is using word problems that would help support their conceptual understanding of fractions. These word problems should connect their daily life activities with concepts they would encounter when learning about fractions. Such questions also would help students understand that division doesn't always have to make numbers smaller because they will be able to read division problems relating to their daily lives that do not reduce numbers.

Sharp suggested posing word problems as a means to help student gain better understanding of fractions (2002):

Here I have $2 \frac{1}{4}$ cups of orange juice. I take medicine each day and my doctor wants me to limit the amount of orange juice I drink when I take my medicine. I can have $3 / 4$ cups of orange juice each day with my breakfast. For how many days can I have orange juice?

(Whole number answer)

Although most students in this study chose to represent their fractions with money or pizza's and thought it to be the easiest for most other students to understand. We should also consider the cultural differences and varieties. People have different cultures and different lifestyles. This means that while money might be an easy concept for middle-class children to relate to, it might be considered to be very hard by children of poor communities. Racial, gender, and socio-economic status of children need be considered when teachers try to convey fractions to students using word problems or pictorial representations (Sleeter, 2005). They need to try to address most of the children's backgrounds within their examples.

Another issue is that students should not be allowed to use calculators at early grades to calculate fractions. This will help students learn to rely more on paper and pencil calculations, which will allow a more persistent and deeper understanding and memorizing of calculation methods with fractions. When students use calculators their sense of number is reduced. They give complete trust to the calculator and they end up being convinced by false answers, generated by mistaken finger hits perhaps, yet the students will lose the ability to use any reasoning in examining their answers. For example: if a student tries to calculate $15 / 5$ and he accidentally hits $5 / 5$ and gets one for an answer, he wouldn't use reasoning to see that his answer isn't correct and that $15 / 5$ cannot be equal to one. He would just give one as an answer.

Furthermore, it is essential for teachers to understand that students bring a form of informal knowledge, which they acquire from their outside lives, into school (National Research Council, 2001). Teachers need to be able to evaluate the amount of the information each student has and the correctness of this information. This knowledge 
should be nurtured and attended to by teachers because it could be the basis for a well-founded understanding of fractions. An example of this informal knowledge can be the notion of sharing. Children learn to share at a very young age, and this concept ideally is the basis for understanding fractions.

\section{References}

Aksu, M. (1997). Student performance in dealing with fractions. The Journal of Educational Research, 90(6), 375-380. https://doi.org/10.1080/00220671.1997.10544595

Ashlock, R. B. (2001). Error patterns in computation: Using error patterns to improve instruction. Prentice Hall.

Durkin, K., \& Rittle-Johnson, B. (2015). Diagnosing misconceptions: Revealing changing decimal fraction knowledge. Learning and Instruction, 37, 21-29. https://doi.org/10.1016/j.learninstruc.2014.08.003

Flores, J., \& Franklin, M., Huynh, T., \& Sprague, J. (2008). Fraction in Elementary Grades. EeeWiki. Retrieved December 5, 2009, from http://eee.uci.edu/wiki/index.php/Fraction

Mcleod, R., \& Newmarch, B. (2006). Maths4life fractions Booklet. National Research and Development Centre for Adult literacy and numeracy. Retrieved Dec, 5, 2009, from http://www.nrdc.org.uk/publications_details.asp?ID=69

National Research Council. (2001). Adding it up: Helping children learn mathematics. In J. Kilpatrick, J. Swafford, \& B. Findell (Eds.), Mathematics Learning Study Committee, Center for Education, Division of Behavioral and Social Sciences and Education. Washington, DC: National Academy Press.

Sadi, A. (2007). Misconceptions in numbers. UGRU Journal, 5, 1-7.

Sarwadi, H. R. H., \& Shahrill, M. (2014). Understanding students' mathematical errors and misconceptions: The case of year 11 repeating students. Mathematics Education Trends and Research, 2014, 1-10. https://doi.org/10.5899/2014/metr-00051

Sharp, J., \& Adams, B. (2002). Children's constructions of knowledge for fraction division after solving realistic problems. Journal of Educational Research, 95(6), 333-347. https://doi.org/10.1080/00220670209596608

Tirosh, D. (2000). Enhancing prospective teachers' knowledge of children's conceptions: The case of division of fractions. Journal for Research in Mathematics Education, 5-25. https://doi.org/10.2307/749817

Vamvakoussi, X., \& Vosniadou, S. (2010). How many decimals are there between two fractions? Aspects of secondary school students' understanding of rational numbers and their notation. Cognition and instruction, 28(2), 181-209. https://doi.org/10.1080/07370001003676603

Weinberg, S. L. (2001, April). Is there a connection between fractions and division? Students' inconsistent responses. Paper presented at the Annual Meeting of the American Educational Research Association, Seattle, WA.

\section{Copyrights}

Copyright for this article is retained by the author(s), with first publication rights granted to the journal.

This is an open-access article distributed under the terms and conditions of the Creative Commons Attribution license (http://creativecommons.org/licenses/by/4.0/). 